DA ADHNE

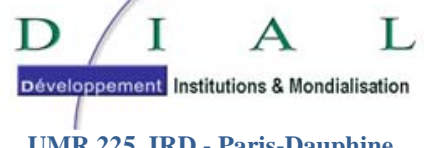

UMR 225 IRD - Paris-Dauphine

Institut de recherche pour le développement

DOCUMENT DE TRAVAIL

DT/2015-11

\title{
Back to Square One - Socioeconomic Integration of Deported Migrants
}

Anda DAVID

UMR DIAL 225

Place du Maréchal de Lattre de Tassigny 75775• Paris Cedex 16•Tél. (33) 0144054542 • Fax (33) 0144054545 • 4, rue d'Enghien• 75010 Paris • Tél. (33) 01532414 50• Fax (33) 0153241451

E-mail : dial@dial.prd.fr $•$ Site : www.dial.ird.fr 


\title{
BACK TO SQUARE ONE - SOCIOECONOMIC INTEGRATION OF DEPORTED MIGRANTS
}

\author{
Anda David \\ PSL, Université Paris-Dauphine, \\ LEDa, IRD UMR DIAL, 75016 Paris, France, \\ Universidad Autonoma de Madrid, Madrid, Spain \\ david@dial.prd.fr
}

\section{Document de travail UMR DIAL}

Juillet 2015

\begin{abstract}
This paper addresses the issue of socioeconomic integration of forced return migrants, focusing on the Maghreb countries. Starting from the hypothesis that the return has to be prepared, we test whether a disruption in the migration cycle (such as deportation) increases the individual's vulnerability and affects his integration from both a structural and sociocultural point of view, using the 2006 MIREM survey. We find that forced returnees are more vulnerable to negative labour market outcomes compared to voluntary returnees. The absence of forced returnees from the labour market, or their underperformances, creates a net loss for the origin country and also incentives to re-migrate. The negative effect is statistically significant not only immediately after return, but also in the long run, at survey time. Forced return is also significantly and negatively correlated with sociocultural integration, reflecting a marginalization of deported migrants in their home environment, which may act as a re-emigration incentive.
\end{abstract}

Key words: Return migration, forced migration, deportation, labour market, socioeconomic integration, Maghreb.

\section{Résumé}

Dans ce papier j'analyse l'intégration socioéconomique des migrants qui sont forcés de rentrer dans leur pays d'origine, avec un focus sur les pays du Maghreb. Ayant comme point de départ l'hypothèse que le retour doit être préparé, je teste si une interruption dans le cycle migratoire (telle que l'expulsion) accroit la vulnérabilité des individus et impacte leur intégration, à la fois d'un point de vue structurel et socioculturel, en utilisant l'enquête MIREM. Les résultats montrent que les migrants expulsés sont plus vulnérables et réussissent moins bien sur le marché du travail dans le pays d'origine, par rapport aux migrants qui ont choisi volontairement de rentrer. L'exclusion des rapatriés forcés du marché du travail, ou leur situation précaire, représente une perte nette pour le pays d'origine et résulte en une plus forte incitation à ré-émigrer. L'effet négatif de l'expulsion sur les performances sur le marché du travail est statistiquement significatif juste après le retour, mais également à plus long terme, au moment de l'enquête. Le retour forcé est également significativement et négativement corrélé avec le degré d’intégration socioculturelle, reflétant une marginalisation des migrants expulsés dans leur environnement d'origine.

Mots Clés : Migration de retour, migration forcée, expulsion, marché du travail, intégration socioculturelle, Maghreb.

JEL Code : F22, J24, O15, Z13 


\section{Introduction}

Apart from stirring civil society's outrage, the impact of forced return migration has drawn little attention from policy makers, and researchers are only begining to study the extent of its implications. Immigrants have to face with the issue of integration when they find themselves in a foreign environment, in some cases, governed by unfamiliar norms. At first glance, returning to one's home country should not entangle the difficulties faced by immigrants, but both empirics and return migrants' stories indicate otherwise. Although not of the same order, the challenges in terms of re-integration that await return migrants are comparable to the integration issues of immigrants. One of the reasons is acculturation phenomenon - a concept from the sociological literature which defines the change in an immigrant's behavior and culture induced by the environment at destination (Arowolo, 2000). Values and expectations vary between the moment when an individual leaves the home country and the moment he returns. In addition, Preston and Brown (1993) argue that the environment in which migrants return to differs from the one they left behind.

These different aspects create the need for migrants to readjust to their home countries' contexts. This readjustment is costly. Upon returning, migrants need to reassert their socioeconomic status, a key determinant for a successful return. Finding a job or opening a business can be difficult for return migrants who lack information concerning the codes and practices in place or in the absence of social capital that could provide the needed assistance. Cassarino (2004) highlights the importance of migrants' "willingness to return" and their reintegration. Migrants wanting to return will therefore prepare their return, through resource mobilization and activating social networks.

When migrants are forced to return, whether for administrative reasons (visa or res- 
idence card non-renewed, deportation for illegal migrants etc.) or personal reasons (health problems, family constraints etc.), the end of the migration episode is sudden and does not leave enough time for a suitable preparation. This paper addresses the issue of forced return migrants and their re-integration from both an economic and sociocultural point of view. We are mainly interested in the extent to which forced return affects socioeconomic integration, proxied by a higher vulnerability to unemployment and the degree of sociocultural integration, for which we propose a quantitative indicator based on the work by Fokkema and de Haas (2011). We find that forced return has a lasting negative impact on migrants' reintegration and discuss the implications of this result. The paper also adds a quantitative economic dimension to the existing literature on forced migration, which has included mainly sociological and legal aspects. The following section briefly discusses the relevant findings from the literature, section 3 presents the sample and the forced return migrants' characteristics, while section 4 and 5 are dedicated to the labour market and sociocultural integration. Section 7 concludes.

\section{A brief literature review}

Siegel and Shryock (1973) define a return migrant as a person moving back to the area where he formerly resided. Cassarino (2004) carries out an extended study on the existing theories on return migration, highlighting the main schools. Thus, according to neoclassical economic theory, return has been seen as the result of a failed migration experience (Todaro, 1969). On the contrary, the New Economics of Labour Migration $(N E L M)$ considers that return is a rational decision and the outcome of a predefined strategy (Stark, 1991). In a structural approach theory, Cerase (1974) states that the decision to return rests mainly on contextual factors in both the home and host coun- 
try. According to the transnationalism approach, return is not the end of the migration process but merely a stage (Portes, Guarnizo, and Landolt, 1999). Finally, the literature relative to the social network theory (Nohria and Eccles, 1992) considers that social capital considerably shapes return migration. Ghosh (2000) offers a conciliatory point of view and argues that return depends on the initial motives of migration, the length of time spent abroad and the conditions for return. Finally, Cassarino (2004) studies preparedness and willingness to return, points out the importance of resource mobilization in the decision to return.

The literature on return migration is quite abundant and looks at the various outcomes of migrants upon return. De Vreyer, Gubert, and Robilliard (2009) find that return migrants in WAEMU ${ }^{1}$ countries are better-off than non migrants. However, having migrated to an OCDE country results in a negative relative advantage in terms of labour market participation when education is controlled for. In a study on Uganda, Thomas (2008) shows that return migrants with university degrees have a higher probability of being employed compared to non-migrants having the same degree. The migration form has a significant impact on well-being and Sabates-Wheeler, Natali, and Black (2007)'s study on Ghanaian migrants suggests that traveling with formal documents increases the chances of moving out of poverty. Thus, the success of the migration experience depends on the migrant's legal status. In a recent paper, Mezger Kveder and Flahaux (2013) show that Senegalese migrants returning to Dakar get into entrepreneurial activities, but only because entrepreneurship is a "last resort" activity. Thus, entrepreneurial status indicates a failed migration experience, in the sense that migrants have no financial or social capital upon return. For the Tunisian case, Mesnard (2004b) shows that, despite the fact that return migrants do not benefit from a phenomenon of human

\footnotetext{
${ }^{1}$ West African Economic and Monetary Union
} 
capital accumulation that would entail positive results on the labour market, their migration allows them to overcome credit constraints and invest in small businesses upon return. In a further study, she shows that the funds received by the migrants aimed at helping them overcome this financial constraint and making them return faster to their home countries, might have the opposite effect and thus increase their length of stay in the destination country (Mesnard, 2004a). Using the MIREM database, Mahuteau and Tani (2011) find that returning migrants who acquired university diplomas while abroad have a higher probability of becoming wage-earners upon return, whereas those that chose vocational training tend to become self-employed. The authors conclude that through this channel "they contribute to reducing poverty". Along the same lines, McCormick and Wahba (2001) show that the effects of savings from abroad on returnees' entrepreneurship vary with the education level, with a higher impact of savings for the illiterate returnees. For the case of Finland, Saarela and Finnäs (2009) argue that return migrants have lower odds of employment than non-migrants and the trend is constant over time. They also find a negative impact of migration duration on employment rates of return migrants. Finally, they observe that return migrants experience difficulties in readapting to the Finnish society, which they explain by unobservable characteristics. Duval (2004) shows that frequent return visits generate a positive and significant probability of successful return and reintegration.

This issue of integration has been underestimated in the literature on return migration. Preston and Brown (1993) dicuss this point in the context of returning refugees and argue that the environment to which the migrants return is different from the one they left when migrating and thus they need to re-adapt. Indeed, Howard (1974) and, more recently, Tannenbaum (2007) support the idea that integration upon return is more difficult than the initial integration abroad. Along the same lines, Arowolo (2000) of- 
fers a discussion on return migration, reintegration problems and coping strategies. Finally, Heckmann (2006) suggests a framework to analyse integration and distinguishes between structural integration (which involves access to employment, housing or education) and sociocultural integration (which cover social interactions and the feeling of belonging).

The return migration literature focuses mainly on voluntary return and the few papers that have looked at forced return migration deal with migrants who return from camps after a forced migration. van Hear (1995) finds that the massive involuntary return of 300,000 Palestinians has contributed to Jordan's economic recovery, but the integration of the returnees has been very difficult, with many of them experiencing a "downward" mobility. In a study on 300 Salvadoran deportees, Hagan, Eschbach, and Rodriguez (2008) highlight the cost of this forced return, both for the origin and the destination country. Indeed, on the one hand, deported migrants are often settlers, leaving behind their families, who turn to the US administration for help. On the other hand, origin households back in Salvador suffer as they lose their main source of income. Combining quantitative and qualitative approaches, Mezger Kveder and Flahaux (2013) take interest into "involuntary return" and conclude that migrants that were forced to return have difficulties integrating the labour market and want to remigrate. But they do not offer any quantification of the degree of "integration". 


\section{Forced return migrants}

\subsection{Data and descriptive statistics}

The data we use come from a survey of return migrants in Algeria, Morocco and Tunisia between 2006 and 2007, part of the MIREM project ("Collective Action to Support the Reintegration of Return Migrants in their Country of Origin"). ${ }^{2}$ The sampling procedure is based on a geographical stratification in the three countries, with a focus on regions with high return rates. Thus, in Algeria, the survey covers the wilayas of Algiers, Bejaia in Kabylie and Setif eastwards of the capital and Tlemcen westwards. For Morocco, the survey was conducted in the region of Tadla-Azilal and the coastal regions of Casablanca, Chaouia-Ourdigha and Rabat-Salé-Zemmour-Zaër. In Tunisia, the focus was on the northern governorates of Tunis, Ariana, La Manouba, and Nabeul as well as the governorates of Soussa and Sfax in the center of the country, and of Medenin in the south. In each country, approximately 300 individual interviews were conducted between September 2006 and January 2007.

The whole sample consists of 992 return migrants surveyed in their home countries. Out of the $992,231(23.29 \%)$ were forced or required to return to their home countries, whereas, for the rest, return was a voluntary decision. In order to construct the variable of forced return migration, we only keep those who answered that they were deported, those whose residence permit was not renewed and those who answered that they were forced to return because they had administrative or fiscal problems. We have expanded the sample to these last two categories since a migrant might not admit that he was deported or he could have chosen to leave the country before the authorities had him

\footnotetext{
${ }^{2}$ The project was launched in 2005 and was financed by the European Union and the European University Institute. The results and details for the field surveys can be found on MIREM's website www.mirem.eu
} 
deported.

Since we are interested only in the active population, we drop those who after return are students, housewives, retired or "other". The final sample contains 135 forced returnees.

Deported migrants come mainly from Italy (42\%), France (28\%) and Spain (13\%). They are overrepresented in the sense that, in the whole sample, $57 \%$ of migrants return from France, $16 \%$ from Italy and only $2 \%$ from Spain.

\subsection{Characteristics of deported migrants}

Forced returnees are on average younger than the other returnees. This seems logical, especially according to the NELM theories, in which migrants return once they have attained their objective in terms of capital accumulation, thus after a significant laps of time. This is also confirmed by a longer duration of stay. In terms of education acquired before migrating, the forced returnees have more often a secondary education level. Their destination is also more likely to be a Southern European country, while voluntary returnees mainly come back from Western Europe. We also notice that most of the deportees had emigrated using a tourist visa (almost 65\%), which is a higher proportion compared to the other returnees (30\%). The characteristics of deportees during the migration episode reveal a vulnerable status, with most of them involved in seasonal work or being unemployed. Despite a similar remittance behaviour between the two types of returnees, the forced returnees pay far less frequent visits to their home country. This fact may be linked to their vulnerable status in terms of legal stay in destination country and to tighter financial constraints. An intuitive consequence is a loosening of links with the origin country and a weakening of the social network 
back home. The migrants are therefore less prepared to return, which is accentuated by the low frequency of discussions about return among the deported migrants (more than half declared that they had never discussed about their return, while the percentage is only $13 \%$ among the voluntary returnees). These various elements indicate a lack of preparedness and willingness to leave the destination country which can negatively influence the success of their return. Indeed, we observe that upon return, more than half of the deported were planning to remigrate in the near future and almost $53 \%$ considered that their financial situation worsened compared to the situation before having migrated. They are also less likely to be employers or business owners and more than one third are unemployed upon return (while only $10 \%$ of the voluntary returnees are unemployed).

In order to capture sociocultural integration, we construct an index à la Fokkema and de Haas (2011), adapting it for our database and for the return context. Fokkema and de Haas (2011) compute the degree of sociocultural integration of migrants in the destination country by summing up seven indicators : (1) the extent to which migrants have social contacts with native population; (2) the ethnic nature of migrants' circle of friends; (3) the participation in either native or foreign organizations; (4) having a partner born in the receiving country; (5) the fluency in the dominant language of the destination country; (6) the degree of modernization regarding views on gender roles and parent-child relationships; (7) the ethnic identification. By adding up these various indicators (revalued with a minimum of 0 and a maximum of 1), they obtain an index that increases with a migrant's integration in the host country.

\section{Table 1 should be here.}

Unfortunately, the MIREM survey offers less information and we had to limit our analysis to fewer indicators, especially concerning integration in destination country. 
The first indicator we take into account when building the sociocultural integration index for the host country is frequency of contacts with native friends. The values range between 0 for no contact with native friends to 2 for frequent and very frequent contacts. The second indicator is marrying a native during migration that takes the value 0 if the answer is "no" and 1 if it is "yes". The relations with society in the host country is the third indicator. The migrants were asked to judge their relations with the host society in general using a scale going from "Very bad terms" to "Very good terms". Furthermore, migrants were asked whether they had any difficulties concerning various aspects such as access to housing, discrimination or racism, finding a job, access to healthcare or administrative issues. By adding the various negative answers to these questions, we compute a fourth indicator relative to difficulties encountered during migration (the less difficulties the migrant experienced, the more integrated he is considered to be). Finally, we normalise each of the indicators and sum them up, thus obtaining a sociocultural integration index whose value, ranging from 0 to 4 , increases with a higher degree of integration.

We then compute a "re-integration" indicator along similar lines. As mentioned by Arowolo (2000) and Preston and Brown (1993), upon returning, migrants, who are no longer the same persons as before having migrated, find themselves in an environment that has evolved since their departure. A first indicator that we include is the initial willingness to re-migrate, building on the hypothesis that an individual who wants to re-migrate, will put in less effort to integrate and reciprocally a lack of integration could encourage him to re-migrate. The variable takes the value 1 for "probably or seriously considering to go back abroad", 2 for "not considering it right know or doesn't know" and 3 for "certainly not considering re-migrating". The second indicator is being a member of an association or party, taking the value 1 for "yes" and 0 for "no". Being 
a homeowner is the third indicator since it can be considered as a proxy for the attachment to the home country. Similar to the integration index for the host country, we add two indicators, one relative to the difficulties encountered upon return and one concerning having experienced adjustment problems and code them as to obtain an indicator that decreases with the number of difficulties and adjustment problems encountered (i.e. for those who declare having experienced difficulties in all fields and have serious adjustment problems, the indicator takes the minimum value). Finally, we include an indicator on the declared satisfaction with the return on the basis that individuals who are more satisfied with the return will be more integrated. After normalizing and adding the indicators, we compute a re-integration index whose value increases with a higher integration or what can be interpreted as "feeling of belonging".

\section{Table 2 should be here.}

The indicators show that forced return migrants are not necessarily less integrated in the host country. However, they are far less integrated in the home country than the ones who chose to return.

The descriptive statistics might lead to think that the two populations are different and this could explain the differentiated outcomes in terms of socioeconomic integration upon return. We argue that the lower performances on the labour market and the lower

sociocultural integration are not sub-sample specific, but are directly correlated to the lack of preparation linked to the unwillingness to return. We use both a linear regression and an IV-approach in order to identify the forced return effect. However, since the validity of the instrument is difficult to assess and the available data does not allow for the construction of other alternative instruments, we complement our simple regressions with a propensity score matching analysis and sub-sample regressions and find that the 
differences of outcomes remain significant when the two populations are matched. The following sections detail and present the results of these analyses.

\section{Labour market integration}

After having observed that voluntary returnees fare better in terms of labour market outcomes than deported migrants, we try to capture the effect of forced migration on labour performances. Unfortunately, the survey does not enable us to measure these performances through salary, thus we focus on the probability of being unemployed, as unemployment is a crucial dimension of social exclusion and vulnerability (Bhalla and Lapeyre, 1997). Given that the question on unemployment was asked both at the time of return (based on the interviewee declaration) and at the time of the survey, we can capture the influence over time of the variables of interest.

We first estimate a binary choice model for unemployment just after return, controlling for the pre-migration characteristics such as age, sex, birth place, education level, employment status, migration motive and the initial migration intention. Concerning the variables relative to the migration episode itself, we control for the destination, the professional status abroad, having studied, the migration duration, the number of migration episodes. In order to capture the degree of preparedness to return, we control for the frequency of contacts with his family in the home country and for the remittance behaviour, as well as for having gathered information about the return. We then run another regression for the probability to be unemployed at the time of the survey, adding post-return variables such as the return intentions, being a member of an association or a political party and the length of time since return.

Thus, the first model we estimate is the following: 


$$
U_{1 i}=\alpha_{1}+\alpha_{2} \cdot \text { ForcedReturn }_{i}+\alpha_{m} \cdot B M_{m i}+\alpha_{n} \cdot D M_{n i}+\alpha_{r} \cdot A R_{r i}+\epsilon_{i}
$$

with $U_{1 i}$ being the probability for the individual $i$ to be unemployed just after return, ForcedReturn $_{i}$ the probability of having been coerced to return, $B M_{m i}$ a vector of $m$ pre-migration individual characteristics, $D M_{n i}$ a vector of $n$ individual characteristics during migration and $A R_{r i}$ a vector of $r$ individual characteristics after migration.

We estimate a similar model for a $U_{2 i}$ which is the probability of being unemployed at the time of the survey:

$$
U_{2 i}=\beta_{1}+\beta_{2} \cdot \text { ForcedReturn }_{i}+\beta_{m} \cdot B M_{m i}+\beta_{n} \cdot D M_{n i}+\beta_{r^{\prime}} \cdot A R_{r^{\prime} i}+\phi_{i}
$$

with

$$
r^{\prime}>r
$$

The main difference concerns the $A R_{r^{\prime} i}$ vector because it includes more characteristics, namely those that had varied, and can be measured, between the time of return and the time of the survey.

As mentioned, forced return might be endogenous with respect to the probability of being unemployed, despite controlling for the pre-migration characteristics. In order to limit the bias, we use an instrumental approach. The main problem is that the survey does not provide enough information to find an exogenous instrument. The only variable that seems relevant in terms of determining the probability of being forced to return and not determining the socioeconomic integration after return is a variable on the type 
of documents used to emigrate. Return migrants were asked whether they went abroad using official documents, fake documents or no documents. We will use this variable and recode it as to take the value 1 if the individual emigrated with official documents and 0 if not. The intuition is that those who emigrated with official documents have a lower probability of being forced to return. At the same time, there is little evidence that having emigrated with official documents might impact labour market outcomes after return. One might argue that having the possibility of traveling with official documents is positively correlated with a higher socioeconomic status, thus a lower probability of unemployment, that might persist over time and lower the probability of being unemployed after return. We argue that even if this were the case, this effect is canceled, by controlling for the socioeconomic variables prior to the migration. Since both the dependent variable and the endogenous variable are binary, we cannot use a traditional 2SLS estimation and, following Nichols (2011), we use different specifications with seemingly unrelated bivariate models in order to correct for the endogeneity. This approach implies that the probability if being unemployed is estimated at the same time as the probability of being forced to return, thus purging the coefficient of forced return of any bias. Results are presented in table 3 and, for the sake of brevity, the non significant controls are not presented in the table.

We observe that even if forced migration has no significant impact right after the return, it does have a positive effect over time. Therefore, if deported migrants do not find themselves more often without a job, just upon return, they are more prone to being unemployed over time. This result confirms the hypothesis that if the migrants are not willing and ready to return, they will have difficulties in activating and using their networks in order to find a job. At the same time, their premature return might be seen as a failure not only by themselves, but also by their social network, thus creating a feel- 
ing of rejection, as it was often mentioned in qualitative interviews in the sociological literature.

The Durbin-Watson test indicates indeed that an endogeneity correction is needed for the unemployment probability at the time of the survey. The coefficient for forced return is even stronger when we correct for the endogeneity. Along the same lines, we observe that being a member of an association or political party significantly decreases the probability of being unemployed, thus stressing the importance of being well integrated in a social institution. Also, being a recent returnee (defined as having a time since return lower than the country sample mean) increases the probability of being unemployed, indicating that a certain laps of time is needed for the returnees to put in practice the skills acquired during their migration and become accustomed to their home country's labour market. In terms of controls, we use variables that capture migrants' characteristics before the emigration, during the migration and in the context of return. Concerning the pre-migration variables, as expected, the education level, as well as experience before having migrated (proxied by having worked before migrating) decrease the probability of being unemployed. These results are similar to those of Mezger Kveder and Flahaux (2013) who find persistence in the occupational status. Those that were employed before migrating, have a higher probability of being employed after return. The financial situation before the migration (a categorical variable ranking from 1 "Very good" to 5 "Very bad") has no significant impact on the probability of being unemployed after return, but it is positively correlated with the probability of having been deported. This indicates that those who had (or at least who considered themselves as having) a worse financial situation in the origin country are also those who had a more vulnerable legal status in the destination country and thus found themselves to be more prone to deportation. This variable is probably correlated with the other control variables of economic 
status before the migration, which might explain the lack of significance. It might also strengthen the idea that if the characteristics before (and during) migration might control for a negative selection in the deportation and the unemployment after return (i. e. those who were more vulnerable, less endowed and less connected are more prone to be deported and also have a lower probability to find a job after return).

\section{Table 3 should be here.}

Furthermore, having studied during the migration and having worked as a wage worker before the return have no significant impact on the probability of being unemployed after return, though they are negatively correlated with the probability of being deported. Having been unemployed before returning hinders labour market insertion upon return, suggesting that the unemployment status abroad might have lowered migrants' ability to prepare their return in terms of capital accumulation.

Regarding migration duration, two effects were expected: a longer migration duration might have increased the unemployment probability through a weakening of social ties and a misperception of the origin country's labour market or it might have decreased unemployment probablity since a longer migration duration could be associated with a higher level of capital accumulation and thus a larger choice of activities upon return. The lack of significance of its coefficient indicates that these two effects might offset each-other. The number of migration episodes is also insignificant with respect to the unemployment probability, suggesting that circular migrants do not suffer from a relative isolation from the local labour market, nor do they profit from their migration experiences compared to those that only have one migration episode.

The frequency of contacts with the family while abroad (a variable that goes from 1 for "Every day" to 6 for "Never") and the dummy variable indicating whether the 
migrant has remitted are associated with transnationalisms and should capture the attachment of migrants to their origin countries. Intuitively, among return migrants, those who had more frequent contacts with their families and who remitted, might be more informed about the local labour market and might benefit more from their connections upon return. Thus, they are likely to have a lower probability of being unemployed. Although the signs of the coefficients confirm this intuition, they are not statistically significant. Also, these variables are potentially endogenous, since looking for a job in the origin country while abroad or planning to start a business upon return might increase the frequency of contacts with the origin household and the probability to remit, while also decreasing the probability of being unemployed after return.

The variable indicating whether the return migrant's main destination country is an European one or not does not appear to be correlated with the probability of being unemployed immediately after return. However its coefficient is positive and significant in the regression of the unemployment probability at survey time, suggesting a delayed effect. This result might suggest that those who migrated in Europe were often underemployed, thus they might have acquired less skills and benefited less from their migration experience upon return. Finally, the year of the first migration was added as a control in order to ensure the comparability of migrant cohorts since migration composition of Maghreb countries is rather various across waves, with a very low skilled early migration, mainly for labour reasons and a more recent migration with a higher education level and a larger variety of migration reasons. 


\section{Sociocultural integration}

The psychiatry literature highlighted the importance of sociocultural integration. Fullilove (1996) writes that "human beings have the need and the unavoidable tendency to feel uniquely and intimately related to a place they consider home". We are thus interested in knowing whether migrants who were forced to return integrate as well as those whose decision to return was voluntary. We aim at capturing this feeling of belonging using the sociocultural integration index from Fokkema and de Haas (2011), which we adapt to a context of return.

Our dependent variable is the sociocultural "re-integration" indicator, $R I_{i}$, detailed in section 3 and the model we estimate is the following:

$$
R I_{i}=\delta_{1}+\delta_{2} \cdot \text { ForcedReturn }_{i}+_{m} \cdot B M_{m i}+\delta_{n} \cdot D M_{n i}+\delta_{r} \cdot A R_{r i}+\nu_{i}
$$

with $R I_{i}$ being degree of re-integration of the individual $i$ after return, Forced Return ${ }_{i}$ the probability of having been coerced to return, $B M_{m i}$ a vector of $m$ pre-migration individual characteristics, $D M_{n i}$ a vector of $n$ individual characteristics during-migration and $A R_{r i}$ a vector of $r$ individual characteristics after migration.

Regarding labour market integration, we use an instrumental approach in order to correct for the endogeneity of return migration, confirmed by the Durbin-Watson test. Since sociocultural integration is more likely to be driven by unobservable characteristics which we might not have captured appropriately, we will interpret the regression coefficients as correlations and not determinants. Our variable of interest, forced migration is highly significant in both the linear and instrumented regressions and its coefficient has the expected negative sign. Therefore, having been deported has not only negative consequences on the structural integration (proxied by labour market outcomes), but it 
also seems to impede the migrants' assimilation in their home country environments.

Coming from a rural background has a positive effect on the integration degree, which might indicate stronger social ties in the rural areas compared to the urban ones. The financial situation before migration is negatively correlated to our integration variable. The straightforward interpretation would be that the wealthiest individuals are also those who are better integrated in society. However, the financial situation variable is not an objective measure of wealth, since it is based on the declaration of the interviewees' appreciation of their financial situation and its effect disappears in the instrumented regression. The number of migration episodes has the expected negative effect on the integration indicator. Indeed, a high number of migration episodes implies spending less time in the origin country and thus having fewer opportunities to bond with the home environment and to create social ties. Having migrated to Europe seems to hinder sociocultural integration upon return. Given that the main alternative is having migrated to a Gulf or MENA country, we think that the negative correlation is due to the difference in sociocultural norms between Europe and the three Maghreb countries under analysis. Migrants returning from Europe have assimilated, at least to some extent, the prevalent norms in their destination countries, and their reintegration might require slightly more effort than that of migrants to neighboring countries. As expected, having remitted is positively linked to the sociocultural integration degree since remitting allows the migrant to keep a close relationship with his social network and this will further facilitate his return. Finally, having had children after return or having invested in a project improves integration since it creates the incentive to become more involved in the home environment and, at the same time, it creates opportunities to create social bonds.

Table 4 should be here. 


\section{Conclusion}

Return migration is not always the end of the migration process, but it is a turning point in the life of a migrant. Its success depends on the fulfilling the migrant's expectations, which is strongly linked to his "willingness" and "preparedness" to return, as highlighted by Cassarino (2004). It is also determined by the phase of the migration cycle at which the individual finds himself at the time of return. Disruptions in the migration cycle resulting in a forced return might thus have serious implications for migrants' socioeconomic well-being. Migrants who were forced to return, either by circumstances or by official institutions, are less prepared to make a living in their home countries and are also faced with a less welcoming social environment since their interrupted migration experience might be seen as a failure. Moreover, they themselves might be more reluctant to adapt to this change since it was forced upon them. Despite the increasing interest in this topic from both a policy and a societal point of view, research on forced return remains limited, mainly due to a severe lack of data.

Using a data set on return migrants in Maghreb countries, we analyse the differentiated outcomes in terms of sociocultural and labour market integration of voluntary and forced return migrants and show that the context of migration is crucial to make return a success. We find that forcing a migrant to return will impede his integration in both structural and sociocultural terms. Forced return migrants have higher probabilities of being unemployed, suggesting lower performances on the job market and fewer opportunities. At the same time, they suffer from a lower sociocultural integration in the home environment which is synonym of a lack of feelings of belonging. We find this result to be true even for the voluntary returnees who had initially planned to stay abroad forever, suggesting that readjustment to the home country's sociocultural envi- 
ronment is even more difficult when changes appear in the desired migration process. Unfortunately, the data do not allow a more in-depth analysis of other labour market outcomes or different dimensions of sociocultural integration and a more extensive data set would be needed in order to generalise the results.

The consequence of this difficult socioeconomic integration might be a higher incentive to re-migrate. Given their vulnerable socioeconomic status, returnees will have fewer opportunities to go abroad and may turn to illegal migration. From a public policy

perspective, this is a crucial point to be taken into account, in particular in the light of the high costs of deportation programs. Due to the political dimension to which these programs are often attached in the destination countries, deportation programs should be carefully evaluated in terms of their global economic efficiency, taking into account both the (short-term) re-integration in their origin country of forced return migrants, and the (longer-term) impact of forced return on subsequent (potentially, illegal) remigration. Moreover, with the economic crisis, return migration significantly increased, and at least a part of this increase can be considered as return migration forced by the circumstances. Further research is thus needed in order to identify barriers to return migrants' integration in the case where the decision to return was compelled, and to draw public policy recommendations both towards destination and origin countries.

\section{Bibliography}

Arowolo, O. O. 2000. "Return Migration and the Problem of Reintegration.” International Migration 38 (5):59-82.

Bhalla, A. and F. Lapeyre. 1997. "Social Exclusion: Towards an Analytical and Operational Framework." Development and Change 28 (3):413-433. 
Cassarino, J.-P. 2004. “Theorising Return Migration: The Conceptual Approach to Return Migrants Revisited.” International Journal on Multicultural Societies (IJMS) $6(2): 253-279$.

Cerase, F. P. 1974. "Expectations and Reality: A Case Study of Return Migration from the United States to Southern Italy.” International Migration Review 8 (2):pp. 245262.

De Vreyer, P., F. Gubert, and A.-S. Robilliard. 2009. "Return Migrants in Western Africa: Characteristics and Labour Market Performance." Working Papers DT/2009/06, DIAL (Développement, Institutions et Mondialisation).

Duval, D. T. 2004. "Linking return visits and return migration among Commonwealth Eastern Caribbean migrants in Toronto." Global Networks 4 (1):51-67.

Fokkema, T. and H. de Haas. 2011. "Pre- and Post-Migration Determinants of SocioCultural Integration of African Immigrants in Italy and Spain.” International Migration :no-no.

Fullilove, M. T. 1996. "Psychiatric implications of displacement: Contributions from the psychology of place.” The American Journal of Psychiatry 153(12):1516-1523.

Ghosh, B. 2000. Return Migration: Journey of Hope Or Despair? International Organization for Migration.

Hagan, J., K. Eschbach, and N. Rodriguez. 2008. "U.S. Deportation Policy, Family Separation, and Circular Migration.” International Migration Review 42 (1):64-88.

Heckmann, F. 2006. “Integration and Integration Policies.” Tech. rep., European Forum for Migration Studies. 
Howard, C. G. 1974. “The returning overseas executive: Cultural shock in reverse." Human Resource Management 13 (2):22-26.

Mahuteau, S. and M. Tani. 2011. "Labour Market Outcomes and Skill Acquisition in the Host Country: North African Migrants Returning Home from the European Union.” IZA Discussion Papers 5441, Institute for the Study of Labor (IZA).

McCormick, B. and J. Wahba. 2001. "Overseas Work Experience, Savings and Entrepreneurship amongst Return Migrants to LDCs." Scottish Journal of Political Economy 48 (2):164-78.

Mesnard, A. 2004a. "Temporary migration and capital market imperfections." Oxford Economic Papers 56 (2):242-262.

—. 2004b. "Temporary migration and self-employment: evidence from Tunisia." Brussels Economic Review 47 (1):119-138.

Mezger Kveder, C. L. and M.-L. Flahaux. 2013. "Returning to Dakar: A Mixed Methods Analysis of the Role of Migration Experience for Occupational Status." World Development 45 (C):223-238.

Nichols, A. 2011. "Causal Inference for Binary Regression with Observational Data.”

Nohria, N. and R.G. Eccles. 1992. Networks and Organizations: Structure, Form, and Action. Harvard Business School Press.

Portes, A., L. E. Guarnizo, and P. Landolt. 1999. “The study of transnationalism: pitfalls and promise of an emergent research field.” Ethnic and Racial Studies 22 (2):217237. 
Preston, R.A. and S. Brown. 1993. The Integration of returned exiles, former combatants and other war-affected Namibians: final report. NISER.

Saarela, J. and F. Finnäs. 2009. "Return migrant status and employment in Finland." International Journal of Manpower 30 (5):489-506.

Sabates-Wheeler, R., C. Natali, and R. Black. 2007. "Migration, Legal Status and Poverty: Evidence from Return to Ghana.” Tech. rep., Development Research Centre on Migration, Globalisation and Poverty (University of Sussex).

Siegel, J.S. and H.S. Shryock. 1973. The Methods and Materials of Demography. US Bureau of the Census.

Stark, O. 1991. The migration of labour. Blackwell Publishing Limited.

Tannenbaum, M. 2007. “Back and Forth: Immigrants' Stories of Migration and Return.” International Migration 45 (5):147-175.

Thomas, K. J. A. 2008. "Return Migration in Africa and the Relationship between Educational Attainment and Labor Market Success: Evidence from Uganda.” International Migration Review 42 (3):652-674.

Todaro, M. P. 1969. “A Model of Labor Migration and Urban Unemployment in Less Developed Countries.” The American Economic Review 59 (1):pp. 138-148.

van Hear, N. 1995. “The Impact of the Involuntary Mass 'Return' to Jordan in the Wake of the Gulf Crisis." International Migration Review 29 (2):352-374.

\section{Tables and figures}




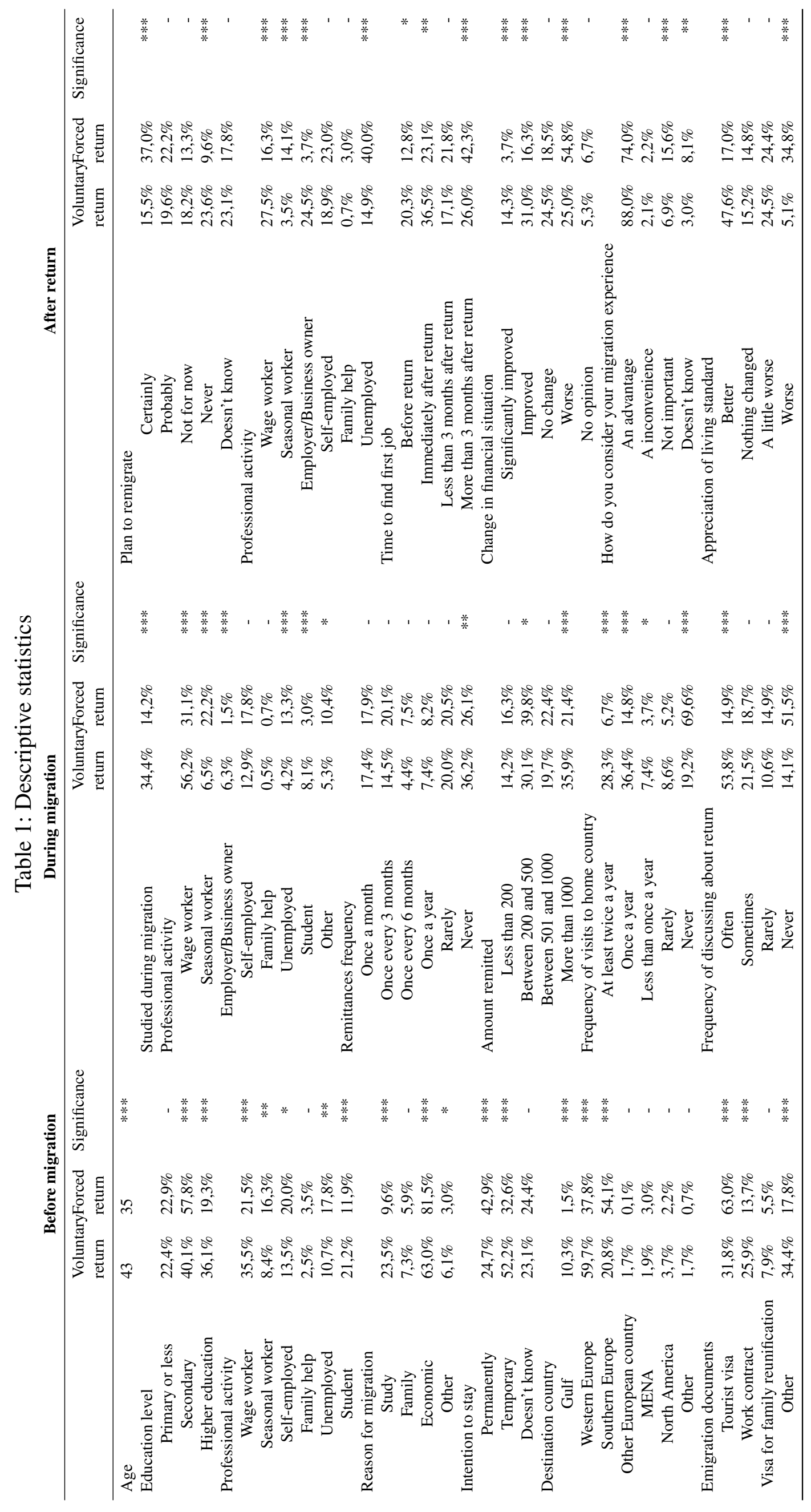


Table 2: Integration index à la Fokkema-de Haas

Voluntary return Forced return Significance

\begin{tabular}{llll}
\hline During migration & 2.74 & 2.46 & $* * *$ \\
After return & 3.78 & 2.74 & $* * *$ \\
\hline
\end{tabular}


Table 3: Labour market integration

\begin{tabular}{|c|c|c|c|c|c|c|}
\hline & \multicolumn{3}{|c|}{ After return } & \multicolumn{3}{|c|}{ Survey time } \\
\hline & $\begin{array}{l}\text { Probit } \\
\text { (1) }\end{array}$ & $\begin{array}{l}\text { Biprobit } \\
\text { (2) }\end{array}$ & $\begin{array}{c}\text { Forced return } \\
\text { (3) }\end{array}$ & $\begin{array}{l}\text { Probit } \\
\text { (4) }\end{array}$ & $\begin{array}{l}\text { Biprobit } \\
\text { (5) }\end{array}$ & $\begin{array}{c}\text { Forced return } \\
\text { (6) }\end{array}$ \\
\hline Forced return & 0.29 & 0.47 & & $0.54 * *$ & $1.76^{* * * *}$ & \\
\hline Age & -0.02 & -0.03 & -0.06 & 0.04 & 0.05 & -0.07 \\
\hline Age squared & 0.00 & 0.00 & 0.00 & -0.00 & -0.00 & 0.00 \\
\hline Male & 0.14 & 0.11 & $0.99 * * *$ & 0.13 & -0.14 & $1.02 * * *$ \\
\hline Rural birth place & -0.04 & -0.03 & -0.30 & -0.07 & -0.00 & $-0.36^{*}$ \\
\hline \multicolumn{7}{|l|}{ Country } \\
\hline Algeria & -0.28 & -0.27 & -0.06 & 0.05 & 0.10 & -0.08 \\
\hline Tunisia & $-0.42 * *$ & $-0.41 * *$ & -0.11 & $-0.49 *$ & $-0.43^{*}$ & -0.24 \\
\hline \multicolumn{7}{|l|}{ Ref: Morocco } \\
\hline Education level before migration & $-0.17 * *$ & $-0.16^{* *}$ & -0.08 & -0.13 & -0.10 & -0.09 \\
\hline Ever worked before migrating & $-0.58^{*}$ & $-0.60 *$ & 0.31 & -0.63 & $-0.86 * *$ & 0.16 \\
\hline Financial situation before migration & 0.08 & 0.07 & $0.26^{* * *}$ & 0.14 & 0.04 & $0.27 * * *$ \\
\hline Studied during migration & 0.04 & 0.06 & $-0.55^{* *}$ & 0.01 & 0.17 & $-0.55^{* *}$ \\
\hline Wage employed during migration & 0.20 & 0.21 & $-0.44 * *$ & 0.14 & 0.27 & $-0.42 * *$ \\
\hline Unemployed during migration & $0.63 * *$ & $0.64 * *$ & -0.28 & 0.50 & 0.46 & -0.28 \\
\hline Migration duration & 0.02 & 0.02 & $-0.05 * *$ & -0.02 & 0.01 & $-0.06 * * *$ \\
\hline Number of migration episodes & 0.11 & 0.11 & -0.00 & 0.02 & 0.03 & -0.03 \\
\hline Frequency of contacts with family & 0.03 & 0.03 & -0.08 & 0.01 & 0.02 & -0.08 \\
\hline Had remitted & -0.06 & -0.06 & $0.33 *$ & -0.24 & -0.27 & $0.35 *$ \\
\hline Destination: Europe & 0.37 & 0.37 & 0.05 & $0.62 *$ & 0.50 & 0.08 \\
\hline Member of association or party & -0.14 & -0.13 & -0.19 & $-0.54 * *$ & $-0.53 * *$ & -0.19 \\
\hline Year of the 1st migration & $0.03 *$ & $0.03 *$ & -0.02 & -0.03 & -0.01 & $-0.04 *$ \\
\hline Recent return & & & & $0.01 * *$ & $0.43 * *$ & 0.16 \\
\hline Has emigrated with official documents & & & $-0.43^{*}$ & & & $-0.41 *$ \\
\hline Constant & -56.80 & -56.96 & 43.34 & 56.97 & 9.46 & $75.57 *$ \\
\hline Athrho & & & -0.11 & & & -1.09 \\
\hline Durbin-Watson, p-value & 0.21 & & & 0.02 & & \\
\hline Observations & 556 & 550 & 550 & 511 & 550 & 550 \\
\hline Pseudo R2 & 0.186 & & & 0.267 & & \\
\hline Controls & Yes & Yes & Yes & Yes & Yes & Yes \\
\hline
\end{tabular}

Note:The controls include labour market outcomes prior to migration, reasons to migrate and the intended length of stay in the destination country. 
Table 4: Sociocultural integration

\begin{tabular}{|c|c|c|c|}
\hline & $\begin{array}{c}\text { OLS } \\
(1)\end{array}$ & $\begin{array}{l}\text { IV } \\
(2)\end{array}$ & $\begin{array}{c}\text { First stage } \\
\text { (3) }\end{array}$ \\
\hline Forced return & $-0.56 * * *$ & $-0.89 *$ & \\
\hline Age & 0.00 & -0.00 & $-0.02 * *$ \\
\hline Age squared & 0.00 & 0.00 & 0.00 \\
\hline Male & -0.08 & -0.03 & $0.14 * * *$ \\
\hline Rural birth place & $0.15 *$ & $0.15^{*}$ & -0.02 \\
\hline \multicolumn{4}{|l|}{ Country } \\
\hline Algeria & 0.13 & 0.10 & -0.06 \\
\hline Tunisia & $0.37 * * *$ & $0.35 * * *$ & -0.02 \\
\hline Ref: Morocco & & & \\
\hline Education level before migration & 0.03 & 0.03 & -0.01 \\
\hline Ever worked before migrating & $0.36 * *$ & $0.42 * *$ & $0.13 * *$ \\
\hline Employed before migration & -0.07 & -0.09 & -0.06 \\
\hline Unemployed before migration & -0.03 & -0.01 & 0.07 \\
\hline Self-employed before migration & -0.21 & -0.21 & 0.02 \\
\hline Financial situation before migration & $-0.06 *$ & -0.05 & $0.04 * * *$ \\
\hline \multicolumn{4}{|l|}{ Migration reason } \\
\hline Study & $0.50 * * *$ & $0.49 * * *$ & -0.03 \\
\hline Family & $0.51 * *$ & $0.50 * *$ & -0.05 \\
\hline Economic & 0.17 & 0.15 & -0.08 \\
\hline Ref: Other & & & \\
\hline \multicolumn{4}{|l|}{ Return intention } \\
\hline Permanent & -0.03 & -0.02 & 0.03 \\
\hline Temporary & 0.09 & 0.07 & -0.05 \\
\hline (ref. Didn't know) & & & \\
\hline Studied during migration & -0.11 & -0.14 & $-0.09 * *$ \\
\hline Ever worked during migration & -0.10 & -0.12 & -0.02 \\
\hline Migration duration & -0.01 & $-0.01 *$ & -0.00 \\
\hline Number of migration episodes & $-0.08 * *$ & $-0.08 * *$ & -0.00 \\
\hline Had remitted & $0.18 * *$ & $0.20 * *$ & $0.05^{*}$ \\
\hline Destination: Europe & $-0.25 * *$ & $-0.23 * *$ & 0.04 \\
\hline Information about return & $-0.14 * * *$ & $-0.11 *$ & $0.09 * * *$ \\
\hline Had children after return & $0.26 * * *$ & $0.26 * * *$ & -0.00 \\
\hline Investment projects after return & $0.46 * * *$ & $0.42 * * *$ & $-0.12 * * *$ \\
\hline Has migrated with official documents & & & $-0.22 * * *$ \\
\hline Constant & $3.06 * * *$ & $3.23 * * *$ & $0.60 * * *$ \\
\hline DurbinWatson, $\mathrm{p}$-value & 0,00 & & \\
\hline Observations & 631 & 631 & 639 \\
\hline R-squared & 0.38 & 0.37 & 0.32 \\
\hline
\end{tabular}

Standard errors in parentheses $* * * \mathrm{p}<0.01,{ }^{*} * \mathrm{p}<0.05,{ }^{*} \mathrm{p}<0.1$ 